\title{
Serial Magnetic Resonance Imaging of Acute Spontaneous Thrombosis of a Giant Intracranial Aneurysm
} -Case Report-

\author{
Kenji KANSAKU, Shinji HiRAI, Eiichi KOBAYAshi, Jun-ichi Ono, \\ and Akira YAMAURA
}

Department of Neurological Surgery, Chiba University School of Medicine, Chiba

\begin{abstract}
A 46-year-old female presented with decreased bilateral visual acuity due to an unruptured non-thrombosed giant aneurysm arising from the left internal carotid artery. After admission, acute thrombosis of the aneurysm occurred spontaneously. Her consciousness and visual acuity temporarily worsened. Serial $\mathbf{T}_{2}$-weighted magnetic resonance (MR) imaging showed the size of the low intensity area near the orifice increased, and the aneurysm ruptured thereafter. Trapping of the aneurysm with a high-flow bypass was performed. Serial MR imaging findings clearly demonstrated the intraluminal structure of the thrombosed giant aneurysm. The aneurysm grew in size after thrombosis. The enlarging signal-void area on $T_{2}$-weighted $M R$ images were indicative of aneurysmal rupture. MR imaging is quite helpful to evaluate the changes of intraluminal thrombosis and size in giant aneurysms.
\end{abstract}

Key words: giant aneurysm, magnetic resonance imaging, spontaneous thrombosis

\section{Introduction}

Thrombosis of giant intracranial aneurysms is well known, ${ }^{1,2,1-10)}$ but neuroimaging of the course of thrombosis in the acute stage is rare. We present a case of acute thrombosis of a giant aneurysm followed by serial magnetic resonance (MR) imaging.

\section{Case Report}

A 46-year-old female experienced decreased bilateral visual acuity in April 1995. She consulted a neurosurgical clinic because of headache and nausea on July 23, 1995. Cerebral angiography showed an unruptured non-thrombosed giant aneurysm arising from the left internal carotid artery, probably at the origin of the ophthalmic artery (Fig. 1 left). A balloon occlusion test of the left internal carotid artery showed the stump pressure decreased to $29 \mathrm{mmHg}$ from $98 \mathrm{mmHg}$ during 15 minutes occlusion. Single photon emission computed tomography with technetium-99m-ethyl cysteinate dimer demonstrated an area of hypoperfusion in the territory of the left middle cerebral artery during the balloon occlusion. She

Received February 6, 1998; Accepted May 20, 1998
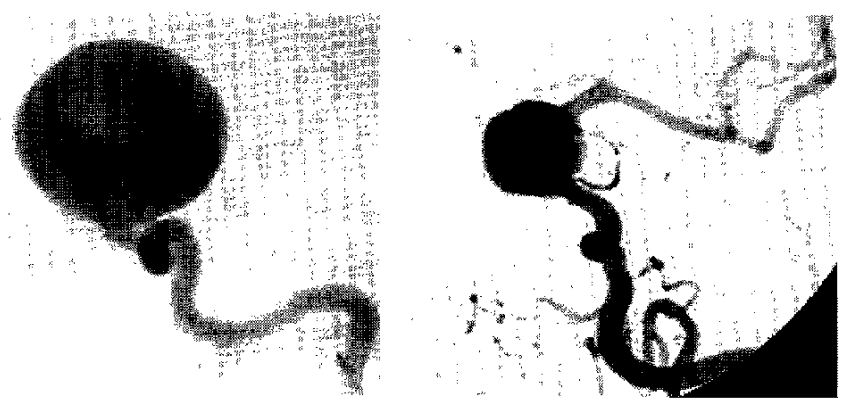

Fig. 1 Left carotid angiograms, showing that prior to spontaneous thrombosis the diameter of the aneurysm was $36 \mathrm{~mm}$ (left: August 15), and following thrombosis the diameter of the aneurysm lumen was $16 \mathrm{~mm}$ (right: September 22).

was referred to our hospital on August 18, 1995. Her visual acuity was 20/400 in the right eye, and 20/200 in the left. Right homonymous hemianopsia was also found.

Her neurological status was stable so neck clipping of the aneurysm was scheduled. However, she experienced sudden onset of headache, nausea, and mild weakness of the right arm on September 1, 

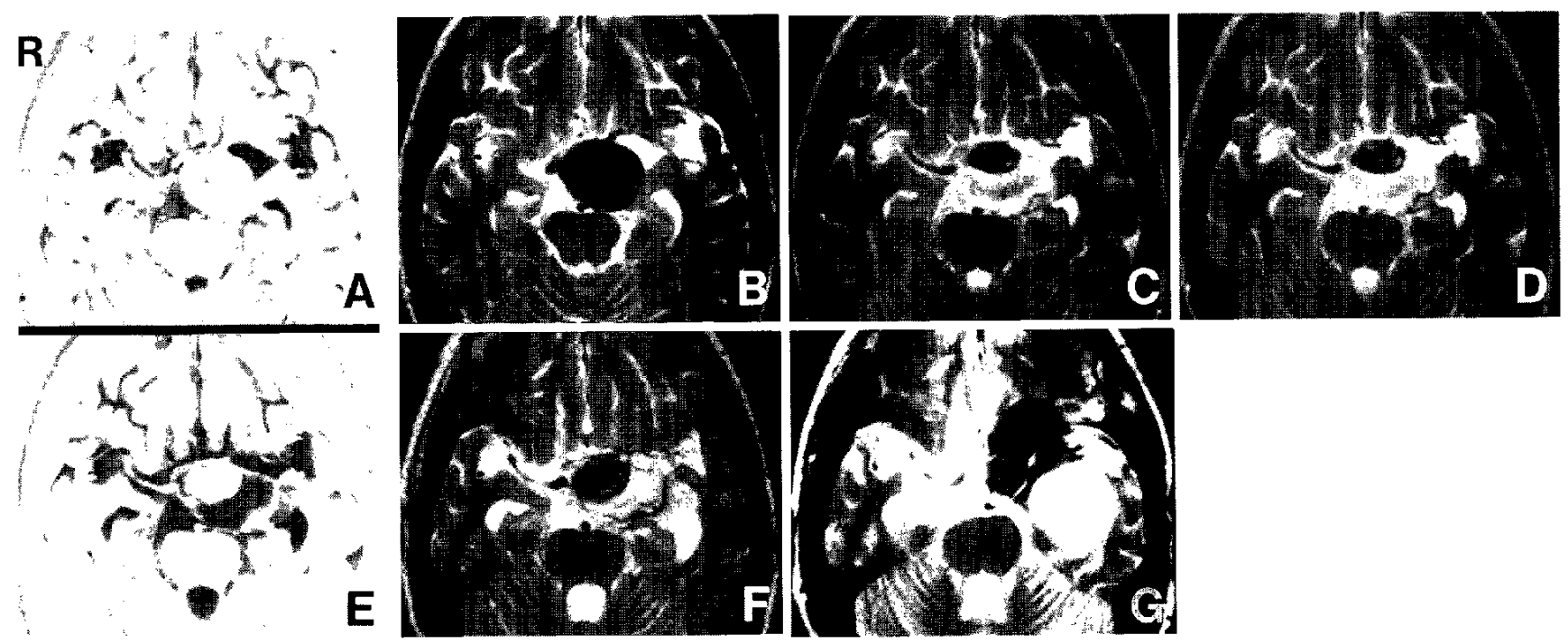

Fig. 2 Serial $\mathrm{T}_{2}$-weighted magnetic resonance images (fast spin echo, repetition time $4000 \mathrm{msec}$, echo time $100 \mathrm{msec}$ ), demonstrating the large giant aneurysm as a signal void area due to the blood flow on August 24, 1995 (A); 4 days after thrombosis as a low intensity area (B: September 5); 13 days (C: September 14), 18 days (D: September 19), and 5 weeks (E: October 5) after thrombosis with a flow void 18,18 , and $23 \mathrm{~mm}$ in diameter, respectively, near the orifice; and 10 days after SAH (F: October 16) with blood clot in the basal cistern; and 7 months after the operation showing artifacts (G: May 26, 1996).

1995. Computed tomography (CT) demonstrated the aneurysm as a round high density mass of $40 \mathrm{~mm}$ maximum diameter, suggesting spontaneous thrombosis of the giant aneurysm. Repeat MR imaging was performed to evaluate the intraaneurysmal structure. Two hours later, she had no additional neurological symptoms except for headache. Her visual acuity did not change. The operation was postponed because the aneurysm might become completely thrombosed. Digital subtraction angiography performed on September 22, 1995 showed a decrease in the size of the aneurysmal lumen compared to prior to the spontaneous thrombosis (Fig. 1 right). Serial $\mathrm{T}_{2}$-weighted images on September 5, 14, 19 , and October 5 showed the size of the low intensity area near the orifice had gradually increased (Fig. 2). She suffered sudden onset of headache, nausea, and vomiting on October 6,1995 . CT showed subarachnoid hemorrhage ( $\mathrm{SAH}$ ) in the basal cistern. An operation was performed on October 24,1995 . The aneurysm could not be obliterated directly because of intraluminal thrombosis and marked arteriosclerosis. A common carotid artery$\mathrm{M}_{2}$ bypass was introduced using a long saphenous vein graft, and the aneurysm was trapped and evacuated.

After the surgery, no further neurological deficits developed, and her visual acuity gradually reco- vered to $20 / 200$ in the right eye, and 20/100 in the left. She left our hospital in a satisfactory condition.

\section{Discussion}

MR imaging of thrombosed giant aneurysms is well known. ${ }^{2,4-7,10)}$ An intraluminal laminated structure is frequently observed, and histological findings show that such a structure represents the thrombosed part of completely or even partially thrombosed giant aneurysms. ${ }^{2)} \mathrm{MR}$ imaging is useful for evaluating whether an intraluminal blood flow remains. ${ }^{51}$ In our case, $T_{1}$-weighted imaging showed a iso to low heterogeneous intensity area in the aneurysm lumen, and $\mathrm{T}_{2}$-weighted MR imaging revealed a high intensity streak-like flow artifact at the center of the aneurysm. Angiography demonstrated a non-thrombosed giant carotid artery aneurysm (Fig. 1). $\mathrm{T}_{2}$-weighted MR imaging in the acute stage after spontaneous thrombosis showed a homogeneous low intensity mass. Serial images showed the peripheral part became high intensity, which is consistent with Gomori's classification. ${ }^{3)}$ The size of the low intensity area representing the flow void near the orifice increased, and SAH occurred subsequently (Figs. 2 and 3). Acute thrombosis followed by thrombolysis was important role in the clinical course of our case. We infer that this increase in size of the flow void on 


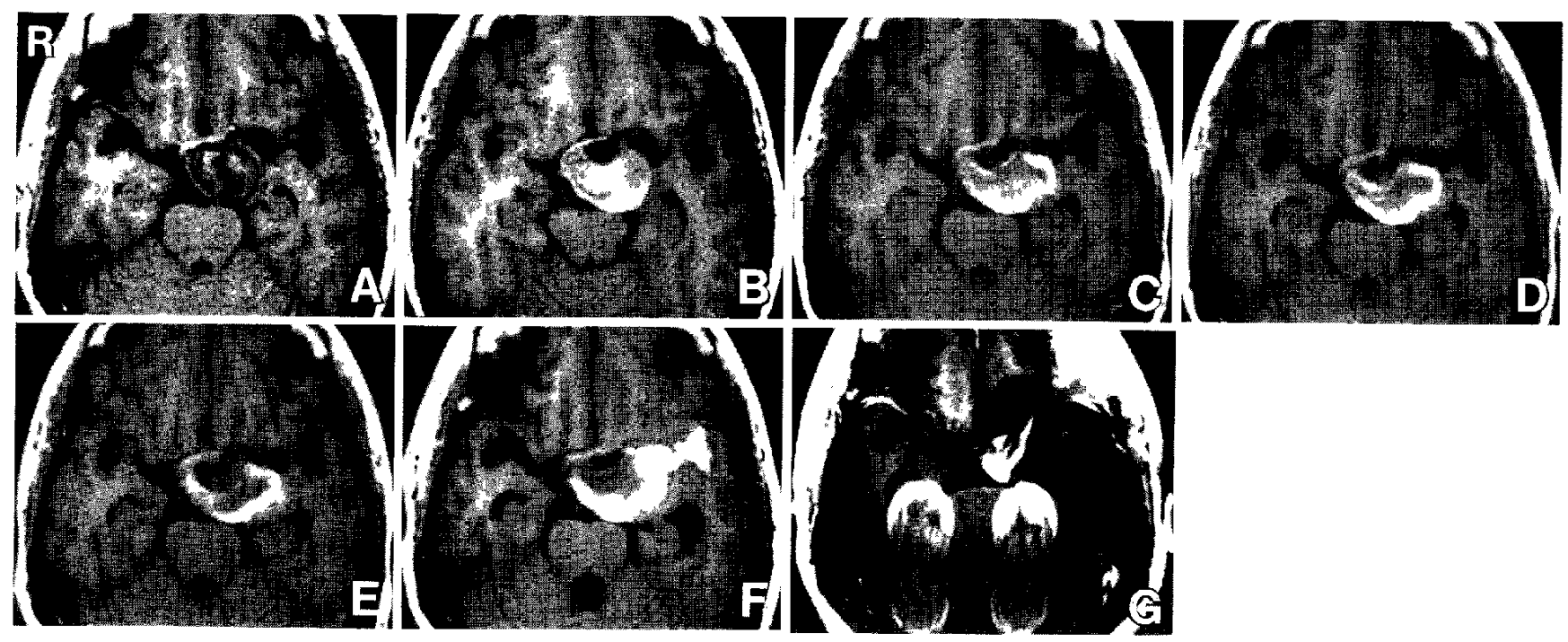

Fig. 3 Serial $\mathrm{T}_{1}$-weighted magnetic resonance images (spin echo, repetition time $500 \mathrm{msec}$, echo time $12 \mathrm{msec}$ ), demonstrating a left internal carotid artery giant aneurysm with heterogeneous iso to low intensity on August 24, 1995 (A), and after spontaneous thrombosis showing enlargement of the aneurysm with peripheral high intensity (B: September 5, C: September 14, D: September 19, E: October 5, F: October 16), and 7 months after the operation showing artifacts due to clips (G: May 26, 1996).

MR imaging is a warning sign of aneurysmal rupture (Table 1). Cerebral angiography is still required to discriminate between remaining blood flow from progressive thrombus formation, which may appears as complex chronological findings on MR imaging.

In our case, the mechanism of acute thrombosis remains problematic. The balloon occlusion test which preceded the thrombosis might have brought a temporary stagnation of blood flow as an initiation of the following process. Then a turbulent flow inherent in giant aneurysms might promote the thrombus formation. Further information about acute thrombosis in similar cases is still needed to explain such event. In contrast, the growth of thrombosed giant aneurysm in chronic stage has been previously documented. ${ }^{1,4,6]}$ The laminated structure on MR imaging supports the presence of repeated hemorrhage within the outer layer, which probably causes the growth in size.

Four of nine cases of partially thrombosed giant aneurysm eventually ended in rupture. ${ }^{9)}$ The presence of a partial clot in giant aneurysms has little prognostic significance and does not alter the management modality or outcome. An essentially completely thrombosed aneurysm with a tiny remnant of the aneurysmal neck ruptured, possibly because of recurrent blood flow into the sac. ${ }^{83}$ Acute deterioration of neurological status occurred following
Table 1 Findings of serial magnetic resonance imaging

\begin{tabular}{|c|c|c|}
\hline & $\mathrm{T}_{1}$-weighted image & $\mathrm{T}_{2}$-weighted image \\
\hline $\begin{array}{l}\text { August 24, } 1995 \\
\text { (spontaneous thrombosis) }\end{array}$ & iso-low heterogeneous & low (artifact + ) \\
\hline September 5 & high & low \\
\hline September 14 & high (artifact + ) & high \\
\hline September 19 & high (artifact + ) & high \\
\hline $\begin{array}{l}\text { October } 5 \\
\text { (subarachnoid hemorrhage) }\end{array}$ & high (artifact + ) & high \\
\hline $\begin{array}{l}\text { October } 16 \\
\text { (operation) }\end{array}$ & high (artifact + ) & high \\
\hline May 26, 1996 & artifact & artifact \\
\hline
\end{tabular}

rapid and massive intraluminal thrombosis of an intracavernous carotid artery aneurysm, and MR imaging demonstrated enlargement of the aneurysm in the acute phase. ${ }^{10)}$ During the increase of aneurysmal size, a signal void indicating a residual blood flow was present near the orifice. From these reported cases, we suggest that a patent flow of the carotid artery allowed the subsequent growth of the aneurysm. However, the aneurysm then decreased in size, after angiography later indicated total occlusion of the carotid artery. Similarly, occlusion of the carotid artery using detachable balloon embolization can reduce the mass effect and eliminate the risk of hemorrhage. ${ }^{7)}$ For the management of partial- 
ly thrombosed giant aneurysm, MR imaging followed by cerebral angiography is essential for evaluation of residual blood flow, both in the aneurysm and in the parent artery. When flow remains in the aneurysmal sac and the sac increases in size, complete obliteration of the aneurysm or the parent artery should be considered.

\section{References}

1) Artmann $H$, Vonofakos D, Muller $H$, Grau $H$ : Neuroradiologic and pathologic findings with growing giant intracranial aneurysm. Surg Neurol 21: 391-401, 1984

2) Atlas SW, Grossman RI, Goldberg HI, Hackney DB, Bilaniuk LT, Zimmerman RA: Partially thrombosed giant intracranial aneurysms: Collection of MR and pathologic findings. Radiology 162: 111-114, 1987

3) Gomori JM, Grossman RI, Hackney DB, Goldberg HI, Zimmerman RA, Bilaniuk LT: Variable appearance of subacute intracranial hematomas on high-field spin-echo MR. Am J Neuroradiol 8: 1019-1026, 1987

4) Katayama $Y$, T'subokawa T, Miyazaki S, Furuichi M, Hirayama T, Himi K: Growth of totally thrombosed giant aneurysm within the posterior cranial fossa: $\mathrm{Di}$ agnostic and therapeutic considerations. Neuroradiology 33: 168-170, 1991

5) Olsen WL, Brant-Zawadzki M, Hodes J, Norman D, Newton TH: Giant intracranial aneurysms: MR imag- ing. Radiology 163: 431-435, 1987

6) Shubiger O, Valavanis A, Wichmann W: Growthmechanism of giant intracranial aneurysms; demonstration by CT and MR imaging. Neuroradiology 29: 266-271, 1987

7) Strother CM, Eldevik P, Kikuchi $Y$, Graves V, Partington C, Merlis A: Thrombus formation and structure and the evaluation of mass effect in intracranial aneurysms treated by balloon embolization: Emphasis on MR findings. Am J Neuroradiol 10: $787-796,1989$

8] Swearingen B, Heros RC: Fatal rupture of a thrombosed giant basilar artery aneurysm. Surg Neurol 23: 299-302, 1985

9) Whittle IR, Dorsch NW, Besser M: Spontaneous thrombosis in giant intracranial aneurysms. J Neurol Neurosurg Psychiatry 45: 1040-1047, 1982

10) Yasui T, Yagura H, Komiyama M, Fu Y, Nagata $Y$, Tamura K, Inoue Y: Mechanism of acute deterioration of the neurological states following rapid and massive intraluminal thrombosis in case of a giant intracavernous carotid artery aneurysm: Demonstration by MR imaging. Surg Neurol 40: 51-56, 1993

Address reprint requests to: K. Kansaku, M.D., Department of Neurological Surgery, Chiba University School of Medicine, 1-8-1 Inohana, Chuo-ku, Chiba 260-8670, Japan. 